\title{
Balloon extraction for the endoscopic removal of proximally migrated pancreatic stent
}

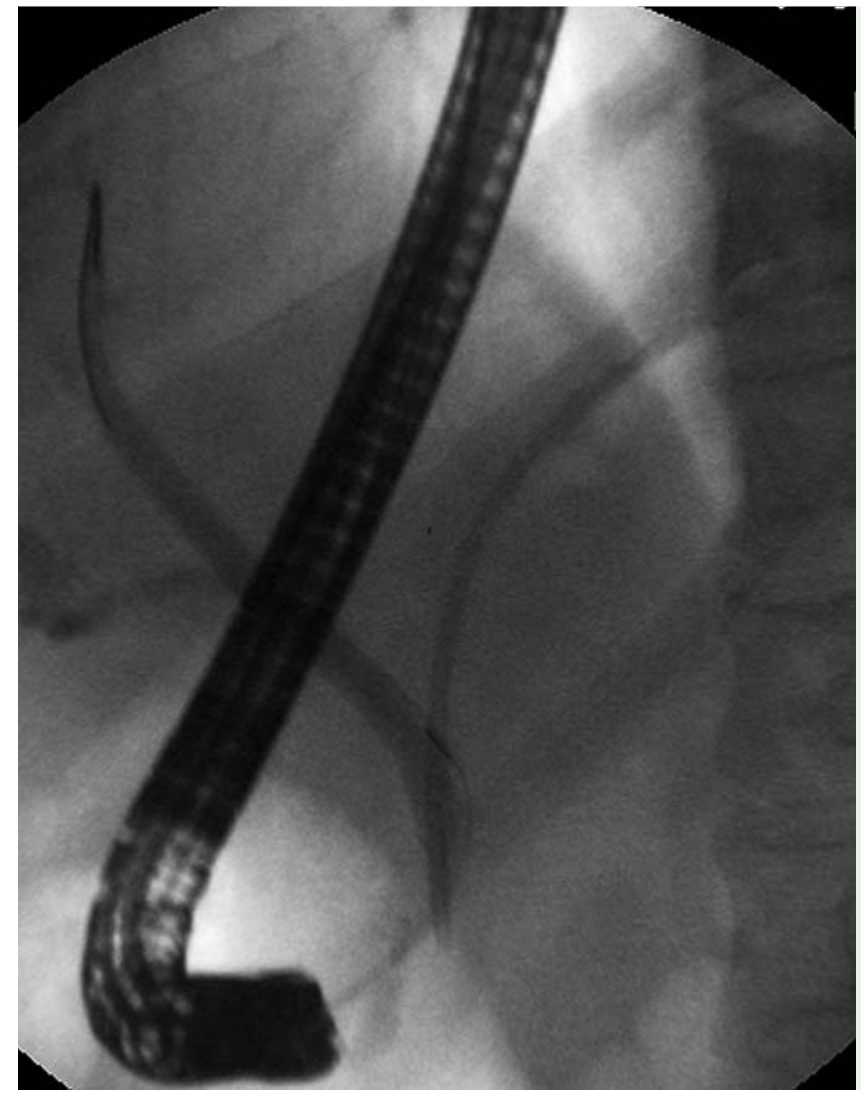

A 33-year-old man underwent endoscopic retrograde cholangiopancreatography (ERCP) for removal of stones in the pancreatic duct. The stones were removed successfully and a plastic pancreatic duct stent (7 Fr, $10 \mathrm{~cm}$; Wilson-Cook, WinstonSalem, North Carolina, USA) was placed in the pancreatic duct to prevent post-ERCP pancreatitis and obstruction.

The patient was admitted 6 months later complaining of abdominal pain. His serum amylase was $118 \mathrm{U} / \mathrm{L}$. ERCP confirmed that the bile duct was not dilated $(\leq 6 \mathrm{~mm})$ but the stent had migrated proximally within the pancreatic duct ( Fig.1). Unfortunately, the stent could not be retrieved due to difficult pancreatic duct cannulation as a result of distal pancreatic duct obstruction by stones and the stent ( $\bullet$ Fig.2). A second ERCP procedure was attempted 3 days later. After pancreatic papillotomy using a needle knife (Wilson-Cook), a guidewire was successfully inserted to the point of stricture by passing it through the stent. First, a basket was used to remove the stones from the
Fig. 1 Fluoroscopic image showing proximal migration of a pancreatic stent within the pancreatic duct. The patient was a 33-yearold man who underwent endoscopic retrograde cholangiopancreatography for removal of stones in the pancreatic duct.

pancreatic duct ( $\bullet$ Fig.3). An extraction balloon (Wilson-Cook) was then inserted over the guidewire to the proximal tip of the stent. The balloon was partially inflated within the pancreatic duct, and withdrawn carefully until the stent could be seen at the ampulla of Vater ( Video 1 ). The stent could then be retrieved by a grasping forceps. The patient's symptoms resolved after this procedure.

Although many devices (basket, snare, and grasping forceps) have been reported to be useful for endoscopic retrieval of proximally migrated pancreatic stents [1-5], we still prefer to try balloon extraction first in order to minimize the mechanical injury to the pancreatic duct [3].

\section{Video 1}

An extraction balloon along the guidewire was passed over the proximal tip of the stent. The balloon was partially inflated within the pancreatic duct and withdrawn carefully until the stent could be seen at the ampulla of Vater. The stent was retrieved using a grasping forceps.

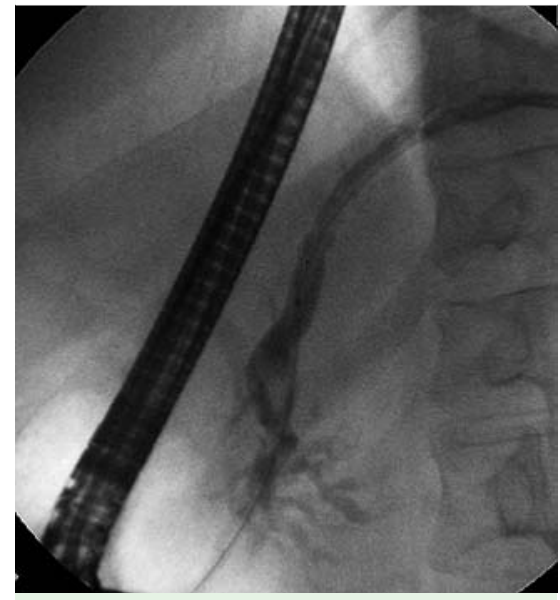

Fig. 2 On pancreatography, the main pancreatic duct was obstructed by stones and the stent.

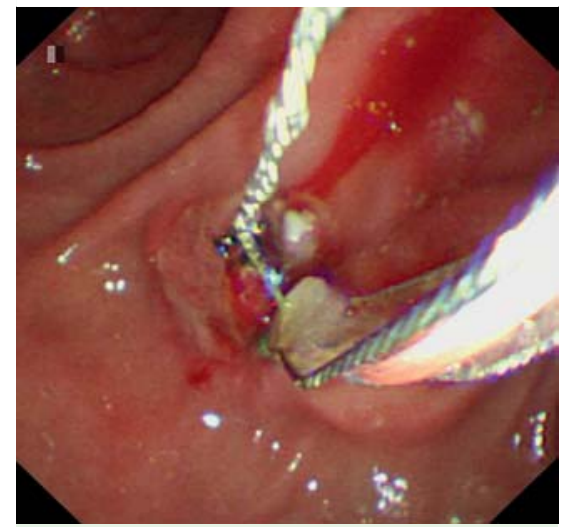

Fig. 3 Stones in the pancreatic duct were removed using a basket.

Endoscopy_UCTN_Code_TTT_1AR_2AZ

\section{Competing interests: None}

\section{Yu-qi He, Ji-heng Wang, Shan Tang, Ge Gao, Jian-qiu Sheng}

Department of Gastroenterology, Beijing Military General Hospital, Beijing, China

\section{References}

1 Lahoti S, Catalano MF, Geenen JE et al. Endoscopic retrieval of proximally migrated biliary and pancreatic stents: experience of a large referral center. Gastrointest Endosc 1998; 47: 486-491 
2 Rerknimitr R, Phuangsombat W, Naprasert $P$. Endoscopic removal of proximally migrated pancreatic stent by a grasping tripod. Endoscopy 2007; 39: E42

3 Price LH, Brandabur IJ, Kozarek RA et al. Good stents gone bad: endoscopic treatment of proximally migrated pancreatic duct stents.

Gastrointest Endosc 2009; 70: 174-179

4 Yoon LY, Moon JH, Choi HJ et al. Wire-guided endoscopic snare retrieval of proximally migrated pancreatic stents after endoscopic papillectomy for ampullary adenoma. Gut Liver 2011; 5: 532 - 535
5 Kim MJ, Han JH, Kang MH et al. Removal of a deeply migrated pancreatic stent in a normal-size pancreatic duct using a modified snare with a cut plastic sheath. Endoscopy 2012; 44: E308 - 309

\section{Bibliography}

DOI http://dx.doi.org/

10.1055/s-0034-1365146

Endoscopy 2014; 46: E186-E187

(c) Georg Thieme Verlag KG

Stuttgart · New York

ISSN 0013-726X
Corresponding author

\section{Jian-qiu Sheng}

Department of Gastroenterology Beijing Military General Hospital Nanmenchang 5\#

Dongcheng District

Beijing 100700

China

Fax: +86-10-66721168

jianqiu@263.net 